\title{
Identification of cleaning staff's habits of personal hygiene and evaluation of the effectiveness of the training carried out
}

\author{
Aliye BULUT ${ }^{1}\left(\mathbb{D}\right.$, Cagla YIGITBAS ${ }^{2}$ (D), Muge OZGULER ${ }^{3}$ (D)
}

\author{
${ }^{1}$ Department of Midwifery, Faculty of Health Sciences, Gaziantep Islamic Science and Technology University, Gaziantep, Turkey. \\ ${ }^{2}$ Department of Midwifery, Faculty of Health Sciences, Giresun University, Giresun, Turkey. \\ ${ }^{3}$ Infectious Diseases and Clinical Microbiology, Elazig Fethi Sekin City Hospital, Elazig, Turkey. \\ Corresponding Author: Aliye BULUT \\ E-mail: aliyedemirok@yahoo.com
}

Submitted: 16.04.2020 Accepted: 03.07.2020

\section{ABSTRACT}

Objective: In this research, in which the effectiveness of the training given to the cleaning staff who are likely to be carriers for pathogens was investigated, it was also examined whether the socio-demographic characteristics of the participants lead to any difference in their hygiene practices.

Materials and Methods: Training on hygiene was given to the participants by a physician who is specialized in the field of infection. Their knowledge before and after the training was evaluated.

Results: It was determined that the rate of desired responses in correct practices regarding hygiene was low, and that there was a change in the scores related to some areas (frequency of going to the dentist, wrong practices in hair hygiene, face towel, hand cleaning material, foot towel practices) after training.

Conclusion: In the research, the effect of health training provided to cleaning staff on knowledge and behavior was examined. As a result of the research, it was observed that there was a general positive increase related to the hygiene issues in the level of knowledge and behavior of the cleaning staff.

Keywords: Cleaning staff, Hygiene, Before and after training

\section{INTRODUCTION}

According to the World Health Organization (WHO), hygiene is the total of conditions and practices for protecting health and preventing the spread of diseases [1].

Personal hygiene is called personal care practices that enable individuals to protect and maintain their health. Personal care, on the other hand, is the whole of activities that are initiated and implemented by the individual aimed at maintaining life, health and well-being. It is the implementation of the practices necessary for individuals' own health by the individuals themselves instead of expecting others to implement them on their behalf [2].

In today's societies where personal hygiene is very important, it is possible to provide a happier, more peaceful and successful education system by taking all necessary precautions for the continuation of a healthy life in public life areas that are closely related to human health. In order to achieve this goal, attention should be paid to the interaction between students at the center of the education system, university and environment, and efforts should be made to create a healthier environment by acting in accordance with personal hygiene and health practices as much as possible. When the literature is analyzed, it is seen that the studies conducted on health and hygiene education in the institutions providing education focus mostly on determining the health knowledge levels and health behaviors of the students. In studies conducted on personal hygiene in all educational institutions, it was determined that the correct hand washing rate among students was low and that the physical environment of educational institutions should have a setting that lends itself to cleaning $[3,4]$.One of the most important parts of this environment is undoubtedly the cleaning staff working in educational institutions. For this reason, considering that it can be important in terms of school health in all educational institutions and beneficial results would be obtained, in this study, it was aimed to determine the personal hygiene habits of cleaning staff working in a university and to evaluate the effectiveness of the training activity carried out.

How to cite this article: Bulut A, Yigitbas C, Ozguler M. Identification of cleaning staff's habits on personal hygiene and evaluation of the effectiveness of the training carried out. Marmara Med J 2020;33:(3):153-159, doi: 10.5472/marumj.816910 


\section{MATERIAL and METHODS}

The research had a quantitative research design with a semiexperimental type including before-training and after-training comparison. The data were collected between June and December 2019. The study had a relational design as it relied on the measurements of the participants related to the dependent variable before and after the procedure. The population of the research consisted of 97 cleaning staff working in a state university in a provincial center, and the sample of the study consisted of cleaning staff $(n=94)$ working at the university during the data collection process who responded to the questionnaire before and after the training. Some trainings were explained theoretically within the scope of its content, and some trainings were delivered as practical training (hand hygiene, tooth brushing, eye cleaning, nail cutting, etc). The participation rate in the research was $96.9 \%$.

The before-training test was applied to the participants in the meeting room in 40 minutes under the control of one of the research assistants. In order to obtain objective data in the test, codes were assigned to the questionnaire forms of the participants, and in order for these codes to be remembered, the identity information and codes of the participants were listed. The list was entrusted to the head of the cleaning staff who did not participate in the study, and the participants were asked to memorize their codes. Then, the participants were divided into groups of 20, and each group was provided with face-toface training by a specialist physician in infectious diseases. The after-training test was administered by the researchers through face-to-face interview method three months after the training. Fourteen participants who forgot their codes learned their codes from the person who had the code list. The list was then destroyed. All procedures performed in the current study were in accordance with the ethical standards of the institutional ethics committee and with the 1964 Helsinki declaration and its later amendments or comparable ethical standards. This study was approved by Bingöl University Ethics Committee (Approval date and number: 15.04.2019; 92342550/044 - E.8055). Before the data for the study started to be collected, the participants were informed that they could withdraw from the study in accordance with the principle of 'Autonomy' for the purpose of the protection of participants' rights, and the 'Informed Consent Form" was presented to them. The principle of 'Confidentiality' was respected during the study; it was ensured that the identity of the participant and the data obtained were kept confidential. The questionnaires belonging to the study were distributed to and collected from the participants via a research assistant in order not to influence the voluntariness of the participants and direction of the research. In line with the principle of 'Respect for Human Dignity', the participants were not judged because of their opinions and practices.

\section{Statistical Analyses}

The socio-demographic characteristics of the participants constituted the independent variables of the research, and questions about personal hygiene were determined as the dependent variables. Statistical Package for the Social Sciences-22 (SPSS-22) was used for the analyses; error checks were run and tables were created through the program. Descriptive data were presented in numbers and percentages. Mc Nemar-Bowker analysis was used to analyze the data. The averages were provided with standard deviations, $\mathrm{P}<0.05$ was accepted as the significance level.

\section{RESULTS}

The participants $(50.0 \%)$ in the research were between 3645 years old, and $27.7 \%$ of the participants were females. The average working year of the participants was $8.46 \pm 4.94$ (median:8, min:1, max:29 years), and the average working year as cleaning staff was $6.71 \pm 3.03$ (median:7, min:2, max: 15 years) (Table I).

Table I. Descriptive characteristics of the participants $(N=94)$

\begin{tabular}{|l|c|c|}
\hline Characteristics & Number & $\%$ \\
\hline Age group & 5 & 5.3 \\
\hline Under 25 years of age & 26 & 27.7 \\
\hline Between 26-35 years & 47 & 50.0 \\
\hline Between 36-45 years & 16 & 17.0 \\
\hline Above 46 years of age & & \\
\hline Gender & 26 & 27.7 \\
\hline Female & 28 & 72.3 \\
\hline Male & & \\
\hline Marital status & 81 & 86.2 \\
\hline Married & 13 & 13.8 \\
\hline Single & & \\
\hline Educational level & 4 & 4.3 \\
\hline Illiterate & 2 & 2.1 \\
\hline Literate & 38 & 40.4 \\
\hline Primary school & 20 & 21.3 \\
\hline Secondary school & 25 & 26.6 \\
\hline High school & 5 & 5.3 \\
\hline University & & \\
\hline Total working years & 24 & 25.5 \\
\hline Less than 5 years & 55 & 58.5 \\
\hline Between 6 and 10 years & 15 & 16.0 \\
\hline 11 years and above & 39 & \\
\hline Working year as a cleaning staff & 48 & 51.5 \\
\hline Less than 5 years & 7 & 7.1 \\
\hline Between 6 and 10 years & & \\
\hline 11 years and above & & \\
\hline
\end{tabular}

As seen in Table II, in terms of before-training and aftertraining, it was determined that the variables other than the dependent variables of the frequency of going to the dentist $(\mathrm{P}=0.005)$, the knowledge related to the wrong practice of hair cleaning $(\mathrm{P}=0.046)$, personal or common use of face towel ( $\mathrm{P}$ $=0.002)$, foot towel $(\mathrm{P}=0.001)$ and hand soap $(\mathrm{P}=0.041)$ did not display any difference $(\mathrm{P}>0.05)$. After the training, an increase by $10 \%$ in the rate of those who said they should visit the dentist in 3 months or less was determined. Regarding the wrong practice related to hair cleaning, participants answered that "The hair should be brushed regularly in order to remove dirt and dead hair" in the group after the training with a rate of 
more than $10 \%$ increase. The rate of increase in those who said that oily hair should be washed more frequently was around $8 \%$ in the training group. It was determined that the aftertraining group stated that the face towel should belong to the person with a $5 \%$ increase. On the other hand, following the training, it was determined that the training group stated that the foot towel should belong to the person with an increase of approximately $18 \%$. Those who stated that hand soap should belong to the person were found to increase by $10 \%$ in the group after the training.

Table II. Status of participants' hygiene behaviors before and after training $(n=94)$

\begin{tabular}{|c|c|c|c|}
\hline Hygiene Behavior & $\begin{array}{c}\text { BT } \\
\text { n }(\%)^{* *}\end{array}$ & $\begin{array}{c}\text { AT } \\
\mathbf{n}(\%)^{* *}\end{array}$ & $\begin{array}{c}\text { Test } \\
\text { Value* }^{*}\end{array}$ \\
\hline \multicolumn{4}{|l|}{ The effects of general body cleanliness } \\
\hline It enables the odor of the body to be expelled. & $7(7.4)$ & $13(13.8)$ & \\
\hline It relieves the individual psychologically. & $11(11.7)$ & $11(11.7)$ & $\mathrm{p}=0.573$ \\
\hline It removes some microorganisms from the skin. & $15(16.0)$ & $14(14.9)$ & \\
\hline It causes the excess fat in the body to be burnt. & $61(64.9)$ & $56(59.6)$ & \\
\hline \multicolumn{4}{|l|}{ Frequency and form of body cleaning } \\
\hline The body needs to be washed with soap and rinsed every two weeks. & $13(13.8)$ & $11(11.7)$ & \\
\hline The body needs to be washed with soap and rinsed every day & $41(43.6)$ & $44(46.8)$ & $\mathrm{p}=0.170$ \\
\hline The body needs to be washed with soap and rinsed once a week & $9(9.6)$ & $19(20.2)$ & \\
\hline Taking a shower without soap is necessary every morning. & $31(33.0)$ & $20(21.3)$ & \\
\hline \multicolumn{4}{|l|}{ Which one do you apply to remove odors such as sweat other than having a bath? } \\
\hline I use deodorant. & $33(35.1)$ & $30(31.9)$ & \\
\hline I wash my body parts such as armpits with soap and water. & $25(26.6)$ & $16(17.0)$ & $\mathrm{p}=0.209$ \\
\hline I change my underwear every day. & $29(30.9)$ & $36(38.3)$ & \\
\hline I wipe my body parts such as armpits with a soapy washrag. & $4(4.3)$ & $6(6.4)$ & \\
\hline Other & $3(3.2)$ & $6(6.4)$ & \\
\hline \multicolumn{4}{|l|}{ How do you clean your face? } \\
\hline I wash my face with water in the morning and at night before going to bed. & $33(35.1)$ & $26(27.7)$ & \\
\hline I wash it with water and suitable soap in the morning and at night. & $17(18.1)$ & $24(25.5)$ & $\mathrm{p}=0.506$ \\
\hline I wash it with soap and water in the morning, at night before bedtime and during the day. & $40(42.6)$ & $40(42.6)$ & \\
\hline Other & $4(4.3)$ & $4(4.3)$ & \\
\hline \multicolumn{4}{|l|}{ Do you have your personal towel at work? } \\
\hline Yes & $52(55.3)$ & $57(60.6)$ & $\mathrm{p}=0.359$ \\
\hline No & $42(44.7)$ & $37(39.4)$ & \\
\hline \multicolumn{4}{|l|}{ Do you also wash your hair separately apart from taking a bath? } \\
\hline Yes & $81(86.2)$ & $84(89.4)$ & $\mathrm{p}=0.453$ \\
\hline No & $13(13.8)$ & $10(10.6)$ & \\
\hline \multicolumn{4}{|l|}{ How often do you visit the dentist? } \\
\hline Never & $20(21.3)$ & $16(17.0)$ & \\
\hline In three months or less & $17(18.1)$ & $27(28.7)$ & $\mathrm{p}=\mathbf{0 . 0 0 5}$ \\
\hline Once in six months & $34(36.2)$ & $28(29.8)$ & \\
\hline In a year or more & $23(24.5)$ & $23(24.5)$ & \\
\hline \multicolumn{4}{|l|}{ How often do you change your toothbrush? } \\
\hline In three months or less & $64(68.8)$ & $63(67.7)$ & \\
\hline Once in six months & $17(18.3)$ & $21(22.6)$ & $\mathrm{p}=0.240$ \\
\hline In a year or more & $7(7.5)$ & $8(8.6)$ & \\
\hline Other & $5(5.4)$ & $1(1.1)$ & \\
\hline \multicolumn{4}{|l|}{ Do you regularly brush your teeth? } \\
\hline Yes & $82(87.2)$ & $84(89.4)$ & $\mathrm{p}=0.687$ \\
\hline No & $12(12.8)$ & $10(10.6)$ & \\
\hline \multicolumn{4}{|l|}{ Why should teeth be brushed regularly? } \\
\hline For health & $54(57.4)$ & $58(61.7)$ & \\
\hline For cleanliness & $5(5.3)$ & $7(7.4)$ & $\mathrm{p}=0.269$ \\
\hline To prevent decay & $31(33.0)$ & $26(27.7)$ & \\
\hline Against bad breath & $2(2.1)$ & $1(1.1)$ & \\
\hline Other & $2(2.1)$ & $2(2.1)$ & \\
\hline \multicolumn{4}{|l|}{ Which one is the wrong practice about hair cleaning? } \\
\hline Hair should be brushed regularly to remove dirt and dead hair. & $8(8.5)$ & $17(18.1)$ & \\
\hline Oily hair should be washed more often. & $25(26.6)$ & $32(34.0)$ & $\mathrm{p}=0.046$ \\
\hline Hair should be brushed quickly and strongly while drying. & $32(34.0)$ & $28(29.8)$ & \\
\hline It should be washed twice a week so that a normal hair oil balance is not disturbed. & $29(30.9)$ & $17(18.1)$ & \\
\hline
\end{tabular}




\begin{tabular}{|c|c|c|c|}
\hline \multicolumn{4}{|l|}{ Which is the right practice for eye cleaning? } \\
\hline Only eyelash bottoms of the eyes should be cleaned with water and soap during each bath. & $6(6.4)$ & $10(10.6)$ & \\
\hline In each bath, eyes should be cleaned by rubbing with soap and water. & $37(39.4)$ & $38(40.4)$ & $\mathrm{p}=0.094$ \\
\hline The eyes do not need special care, if necessary, only the eye secretion accumulating in the eyelash bottoms should be removed. & $22(23.4)$ & $22(23.4)$ & \\
\hline Only eyes should be cleaned with soap and water in the morning. & $29(30.9)$ & $24(25.5)$ & \\
\hline \multicolumn{4}{|l|}{ Which is the right practice for nose cleaning in a healthy individual? } \\
\hline It should be cleaned by inhaling normal saline into the nostrils. & $20(21.7)$ & $13(14.1)$ & \\
\hline Nose wastes should be removed by blowing with running water or a tissue. & $63(68.5)$ & $66(71.7)$ & $\mathrm{p}=0.113$ \\
\hline Only after bathing, nose wastes should be cleaned with a tissue. & $6(6.5)$ & $10(10.9)$ & \\
\hline The nostrils should be cleaned with the help of a foreign object & $3(3.3)$ & $3(3.3)$ & \\
\hline \multicolumn{4}{|l|}{ Which is the appropriate method of hand washing according to the cleaning rules? } \\
\hline It is sufficient to wash your hands by rubbing between the fingers with water. & $1(1.1)$ & $1(1.1)$ & \\
\hline Hands should be washed with an alcoholic solution starting from the wrist level and rubbing between the fingers. & $11(11.7)$ & $11(11.7)$ & $\mathrm{p}=0.401$ \\
\hline Hands should be washed with water only for 15-20 seconds before and after each work. & $30(31.9)$ & $24(25.5)$ & \\
\hline Hands should be washed starting from the wrist level with warm water and soap, rubbing between the fingers. & $52(55.3)$ & $58(61.7)$ & \\
\hline \multicolumn{4}{|l|}{ Which one is the right practice for cutting the fingernails and toenails? } \\
\hline Both should be cut straight. & $44(46.8)$ & $44(46.8)$ & \\
\hline Both should be cut rounded. & $17(18.1)$ & $23(24.5)$ & $\mathrm{p}=0.270$ \\
\hline Fingernails should be cut rounded and toenails straight. & $24(25.5)$ & $19(20.2)$ & \\
\hline Fingernails should be cut straight and toenails should be cut rounded. & $9(9.6)$ & $8(8.5)$ & \\
\hline \multicolumn{4}{|l|}{ Which explains the importance of work clothes in terms of cleanliness and hygiene the best? } \\
\hline Work uniforms protect other clothes from wear and tear. & $5(5.3)$ & $12(12.8)$ & \\
\hline Work uniforms prevent harmful microorganisms from entering the body. & $10(10.6)$ & $10(10.6)$ & $\mathrm{p}=0.175$ \\
\hline They keep other clothes clean and reduce the transmission of harmful microorganisms from the environment to our body and from our body to the environment. & $53(56.4)$ & $55(58.5)$ & \\
\hline Work uniforms make the employee look clean and neat. & $26(27.7)$ & $17(18.1)$ & \\
\hline \multicolumn{4}{|l|}{ Would you like to get information about personal hygiene? } \\
\hline Yes & $76(80.9)$ & $78(83.0)$ & $\mathrm{p}=0.754$ \\
\hline No & $18(19.1)$ & $16(17.0)$ & \\
\hline \multicolumn{4}{|l|}{ What kind of soap do you usually prefer to wash your hands? } \\
\hline Soap bar & $37(39.4)$ & $30(31.9)$ & $\mathrm{p}=0.143$ \\
\hline Liquid soap & $57(60.6)$ & $64(68.1)$ & \\
\hline \multicolumn{4}{|l|}{ How often do you change your socks? } \\
\hline Every day & $87(92.6)$ & $88(93.6)$ & \\
\hline Once a week & $4(4.3)$ & $3(3.2)$ & $\mathrm{p}=0.905$ \\
\hline When it gets dirty and stained & $3(3,2)$ & $3(3,2)$ & \\
\hline \multicolumn{4}{|l|}{ Face Towel } \\
\hline My own & $78(83.0)$ & $88(93.6)$ & $\mathrm{p}=0.002$ \\
\hline Commonly used at home & $16(17.0)$ & $6(6.4)$ & \\
\hline \multicolumn{4}{|l|}{ Foot Towel } \\
\hline My own & $74(78.7)$ & $91(96.8)$ & $\mathrm{p}=0.001$ \\
\hline Commonly used at home & $20(21.3)$ & $3(3.2)$ & \\
\hline \multicolumn{4}{|l|}{ Bath Towel } \\
\hline My own & $89(94.7)$ & $90(95.7)$ & $\mathrm{p}=1.000$ \\
\hline Commonly used at home & $5(5.3)$ & $4(4.3)$ & \\
\hline \multicolumn{4}{|l|}{ Toothbrush } \\
\hline My own & $87(92.6)$ & $93(98.9)$ & $\mathrm{p}=0.070$ \\
\hline Commonly used at home & $7(7.4)$ & $1(1.1)$ & \\
\hline \multicolumn{4}{|l|}{ Hand soap (liquid) } \\
\hline My own & $35(37.2)$ & $45(47.9)$ & \\
\hline Commonly used at home & $54(57.4)$ & $46(48.9)$ & $\mathrm{p}=0.041$ \\
\hline Commonly used in the workplace & $5(5.3)$ & $3(3.2)$ & \\
\hline \multicolumn{4}{|l|}{ Bath washcloth } \\
\hline My own & $83(88.3)$ & $86(91.5)$ & $\mathrm{p}=0.453$ \\
\hline Commonly used at home & $11(11.7)$ & $8(8.5)$ & \\
\hline
\end{tabular}

${ }^{*}$ McNemear Test was performed in binary comparisons and McNemear-Bowker Test was employed in multiple comparisons. ${ }^{* *}$ Percentage of column is taken. BT: Before training, AT: After training

Table III shows the distribution of changes in hygiene behaviors according to the age of the participants. 
Table III. Distribution of changes in hygiene behaviors according to the age of the participants $(N=94)$

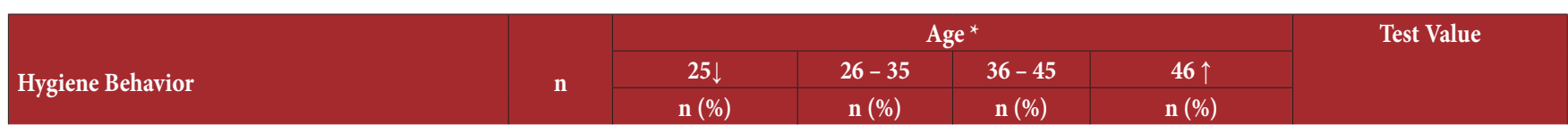

How often do you visit the dentist?

\begin{tabular}{|c|c|c|c|c|c|c|}
\hline \multicolumn{6}{|l|}{ BT } & \\
\hline Never & 20 & $2(40.0)$ & $2(7.7)$ & $8(17.0)$ & $8(50.0)$ & \\
\hline In three months or less & 17 & $2(40.0)$ & $7(26.9)$ & $8(17.0)$ & $0(0.0)$ & $\chi^{2}=18.186$ \\
\hline Once in six months & 34 & $1(20.0)$ & $9(34.6)$ & $20(42.6)$ & $4(25.0)$ & $p=0.033$ \\
\hline In a year or more & 23 & $0(0.0)$ & $8(30.8)$ & $11(23.4)$ & $4(25.0)$ & \\
\hline \multicolumn{6}{|l|}{ AT } & \\
\hline Never & 16 & $1(20.0)$ & $1(3.8)$ & $10(21.3)$ & $4(25.0)$ & \\
\hline In three months or less & 27 & $3(60.0)$ & $9(34.6)$ & $12(25.5)$ & $3(18.8)$ & $\chi^{2}=11.416$ \\
\hline Once in six months & 28 & $1(20.0)$ & $11(42.3)$ & $13(27.7)$ & $3(18.8)$ & $\mathrm{p}=0.248$ \\
\hline In a year or more & 23 & $0(0.0)$ & $5(19.2)$ & $12(25.5)$ & $6(37.5)$ & \\
\hline
\end{tabular}

* Percentage of column is taken. BT: Before - training, AT: After-training

\section{DISCUSSION}

In this study, it was aimed to determine the personal hygiene habits of the cleaning staff working in a university and to evaluate the effectiveness of the training conducted. The population of the research consisted of 97 cleaning staff working in a state university in a provincial center, and the sample of the study consisted of cleaning staff $(n=94)$ working in the university during the data collection process who responded to the questionnaire before and after the training. The participation rate in the research was $96.9 \%$.

The participants $(50.0 \%)$ in the research were between 36-45 years old, and $27.7 \%$ of the participants were females. In terms of before-training and after-training, it was determined that the variables other than the dependent variables of the frequency of going to the dentist, the knowledge on wrong practice related to hair cleaning, personal or common use of the face towel, foot towel and hand soap did not display any difference.

If we are to examine the contributions provided in terms of hygiene after the training one by one, it was determined that there was an increase of approximately $10 \%$ after the training in the rate of those who said "It is necessary to visit the dentist in 3 months or less". On the other hand, the training did not have an impact on the participants in terms of the frequency of tooth brushing and changing tooth brush. In an interventional study, Coşkun and Kara reported that $70 \%$ of students brushed their teeth twice a day and more, that $59.5 \%$ changed tooth brushes every 1-3 months, and that these rates increased significantly after training [5]. Muttappillymyalil et al., stated that $84.6 \%$ of adolescents brushed their teeth twice a day in their research titled 'Oral Health Behavior Among Adolescents in Kerala / India' [6]. In the study, they also reported that $45.5 \%$ of the adolescents stated that they visited the dentist regularly.

The purpose of hand hygiene, which is accepted in personal hygiene practices, is to ensure the disinfection of chemical and physical pests and microorganisms that cause infections. When one cleans his/her hands with water only to have hand hygiene, she/he tries to remove those pathogens through mechanical effect, but complete cleaning cannot be ensured. Therefore, it is mandatory to use soap with water in personal cleaning. Personal hygiene practices and preventive health services are known to reduce certain infections. According to $\mathrm{WHO}$, basic hygiene behaviors such as washing hands with soap, removing stools safely and using clean water are beneficial for improving health [7]. Soap is one of the most effective methods not only for disinfection of the hands but also for the removal of harmful contaminants with allergic effects (nickel, iron and other allergen metals and powders) [8]. Although, normal solid hand soaps and liquid soaps are not different in terms of their effects, soap bars can be sources of contamination due to the environment where they are kept and people leaving the soap uncleaned after using it. Therefore, especially in public places, liquid soaps should be preferred for personal hygiene [9]. In our study, although, the difference was not significant, the rate of cleaning staff choosing liquid soap during hand washing increased by $8 \%$ after the training. The rate of those who stated that hand soap should belong to the person was found to increase by $10 \%$ in the aftertraining group, and this difference was significant in terms of comparison between before-training and after-training periods. In our study, it was determined that the number of participants in the after-training group who stated that the face towel should belong to the person, increased by $10.6 \%$. On the other hand, it was also found that the after-training group stated that the foot towel should belong to the person with an increase of approximately $18.1 \%$. In the study conducted in 2017 on personal hygiene habits of elementary school students in our country, the rate of using towels in the urban area was found to be $63.3 \%$ and $36.7 \%$ in the rural area [10]. In their research in which they investigated the students of two different primary schools in Istanbul, Önsüz and Hidıroğlu, found that $48.3 \%$ of the students studying in Ümraniye had personal towels. In contrast, they determined that $59.4 \%$ of the students studying in Üsküdar had a personal towel [4]. In their interventional research, Coşkun and Kara found that the rate of students' using 
towels after washing their hands was $93.9 \%$ before training, while this rate increased to $95.0 \%$ after training [5].

The appearance of the hair usually gives an idea about the general health of the people and their level of personal hygiene. People with messy and dirty hair are often inadequate in terms of hygiene practices. In such cases, infection-causing factors and parasites can easily be transmitted to dirty hair and scalp. Hair should normally be washed at least once or twice a week. Oily hair types should be washed frequently and appropriate hair washing products should be used [11]. Regarding hair cleaning, it was determined that the participants in the aftertraining group said that "The hair should be brushed regularly in order to remove dirt and dead hair" with an increase of more than $10 \%$. The rate of increase in those who said that oily hair should be washed more frequently was around $8 \%$ in the training group. In different studies conducted on the frequency of taking a bath among primary school students, the frequency of taking a bath every three days and above was found to be between $57.4 \%$ and $69.5 \%[10,12]$. It was found that $67.8 \%$ of the students participating in this research took a bath in three days or more before the training, and this rate went up to 77.8\% after the training. In Arat et al's. research titled 'Personal Hygiene Practices of Boarding Elementary School Second Level Students', it was found that $38.2 \%$ of students washed their hair once every two days and $29.9 \%$ every three days [13]. Coşkun and Kara also found in their research that $67.8 \%$ of the students who participated in the research had a bath every three days or more before the training, and this rate increased to $77.8 \%$ after the training [15]. Our findings are consistent with literature experiments [14-16].

\section{Conclusion and Suggestions}

In the research, the effect of health training provided to cleaning staff on knowledge and behavior was examined. As a result of the research, it was observed that there was a general positive increase related to the hygiene issues in the level of knowledge and behavior of the cleaning staff.

In conclusion, there is a lack of training for the cleaning staff included in this research regarding the work they do and personal hygiene. The rate of using personal materials related to the working environment and using personal materials in the home environment is low. It seems that some behaviors regarding cleaning / hygiene / health are inadequate. Measures and training programs should be increased for the personnel working in cleaning jobs to perform in a more effective and healthy manner. In addition, they should be provided with opportunities to develop hygiene and gain positive behavior starting from childhood. Periodic training sessions should be held within the scope of occupational health for those in this age group.

\section{Compliance with Ethical Standards}

Ethical Approval: This study was approved by Bingöl University Ethics Committee (Approval date and number: 15.04.2019; 92342550/044 - E.8055).
Financial Support: The authors have no relevant financial information to disclose.

Conflict of Interest: The authors have no potential conflicts to disclose.

Authors' Contributions: Concept: A.B., Design: A.B., Education: M.O., Data Collection or Processing: A.B., Analysis or Interpretation: C.Y., Literature Search: A.B., Writing: A.B., C.Y.

\section{REFERENCES}

[1] World Health Organization, https://www.who.int/healthtopics/adolescents/coming-of-age-adolescent-health, http:// www.who.int/topics/hygiene/en/, Access of Date: 01.05.2019.

[2] Uzunçakmak T. The effect of self care training upon self care power in adolescents, Master Thesis, Erciyes University Institute of Health Sciences, Kayseri, 2012.

[3] Yetkin A. Yiğitbaş Ç. Comparison of the personal hygienic habits of freshman and senior students of health college. Journal of Anotalia Nursing and Health Sciences 2008; 11:72-84.

[4] Önsüz MF. Hidiroglu S. Determining personal hygiene practices of students in two different primary school in Istanbul. Meandros Med Dental J 2008;9 : 9-17.

[5] Coşkun M, Kara F. Evaluation of the impact of health education given to students on knowledge and attitudes. Journal of Continuing Medical Education 2015; 24: 55-63.

[6] Muttappillymyalil J, Sreedharan J, Salini K, Divakaran B, Sreedhar S. Oral health behaviour among adolescents in Kerala, India. Italian Journal of Public Health 2009; 6: 218-24.

[7] Özvarış ŞB. Healthcare workers from infection protection. Journal of Continuing Medical Education 1999; 8: 455-47.

[8] Rotter M. Procedures for hand hygiene in German-speaking countries. Zentralbi Hyg Umweltmed 1996;199 (2-4): 334-49.

[9] Namura S, Nishijima S, McGinley KJ, Leyden JJ. A. study of the efficacy of antimicrobial detergents for hand washing: using the full-hand touch plates method. Dermatol J 1993; 20 : 88-93. doi: 10.1111/j.1346-8138.1993.tb03837.x.

[10] Yllmaz E, Özkan S. Comparison of the personal hygiene habits of the primary school students in two different living area of the district. Firat Health Services Magazine 2009; 4:19-33.

[11] Yllmaz Irmak $H$. The evaluation of the attitude and the behaviour of the patients with the information about personal hygiene. Master Thesis. Cumhuriyet University Institute of Health Sciences. Sivas, 2015.

[12] Kaya M, Aslan D. An intervention study on "handwashing" among secondary school students in Ankara. Erciyes Medical Journal 2009;31:135-43.

[13] Arat A, Şimşek I, Erdamar G. The second grade students' practises about personal hygiene in regional boarding primary school. The Journal of the Industrial Arts Education of Faculty of Gazi University 2014; 33: 58-72.

[14] Ünal MM, Özmen Toğay S. Determination of hygienic condition in surface samples and hygiene awareness of working staff of hospital kitchens in Istanbul. Turkish Bulletin 
of Hygiene and Experimental Biology 2017; 74: 307-20. doi: 10.5505/TurkHijyen.2017.30164.

[15] Ismail FH, Chik CT, Muhammad R, Yusoff NM. Food safety knowledge and personal hygiene practices amongst mobile food handlers in Shah Alam, Selangor. Procedia-Social And Behavioral Sciences 2016; 222: 290-8. doi: 10.1016/j. sbspro.2016.05.162.
[16] Sormaz Ü, Şanlier N. The impact of compulsory hygiene training given to employees working in the sector of food and beverages services on their hygiene-related habits, behaviours and knowledge. Journal of Human Sciences 2017;14: 1356-69. doi: 10.14687/jhs.v14i2.4545 